\title{
Performance of Appended Wire Mesh Packing in Sieve Tray Distillation Column of Ethanol-Water System
}

\author{
Fadlilatul Taufany ${ }^{1}$, Nonot Soewarno ${ }^{1}$, Melvina Eliana Sutanto ${ }^{1} \&$ Indi Raisa Girsang ${ }^{1}$ \\ ${ }^{1}$ Department of Chemical Engineering, Sepuluh Nopember Institute of Technology, Indonesia \\ Correspondence: Fadlilatul Taufany, Department of Chemical Engineering, Sepuluh Nopember Institute of \\ Technology, Surabaya, 60111, Indonesia. E-mail: taufany99@yahoo.com
}

Received: May 4, 2015

doi:10.5539/mas.v9n7p148
Accepted: June 5, 2015

Online Published: June 30, 2015

\begin{abstract}
For the separation process in liquid-liquid mixture such as ethanol-water mixture, a sieve tray distillation column is an alternatif for affordable process and maintenance. However to date, this sieve tray system is still currently having a lower Murphee efficiency and smaller interfacial area, as compared to other tray system, that is, either a bubble cap or valve tray. Therefore it is of important to optimize the performance of sieve tray distillation by means of adding the wire mesh packing on that tray, as being the aim of the present study. This study is conducted by using a batch sieve tray distillation system, where the wire mesh packing is added on the third tray that is calculated from the top of the column, to avoid flooding inside the column. Here the resulting fermented molasses of containing a $10 \%$ volume of ethanol is used as a mixture distillation feed. The height of the wire mesh packing being studied is varied as $5 \mathrm{~cm}, 3 \mathrm{~cm}$, and $2 \mathrm{~cm}$. Our results showed that the Murphee efficiency obtained by the variation of the packing height of $5 \mathrm{~cm}, 3 \mathrm{~cm}, 2 \mathrm{~cm}$ and without packing were $73.5 \%, 66.27 \%$, $56.86 \%$, and $46.7 \%$ respectively, and were increased by subsequent level of the packing height. The corresponding hydrodynamic properties of this appended packing sieve tray distillation by means of the interfacial area were $11.88 \mathrm{~cm}^{2} / \mathrm{cm}^{3}, 0.48 \mathrm{~cm}^{2} / \mathrm{cm}^{3}$, and $0.32 \mathrm{~cm}^{2} / \mathrm{cm}^{3}$, while its pressure drop measured from the water manometer height were $38.33 \mathrm{~cm} \mathrm{H}_{2} \mathrm{O} / \mathrm{m}, 30 \mathrm{~cm} \mathrm{H}_{2} \mathrm{O} / \mathrm{m}, 10 \mathrm{~cm} \mathrm{H}_{2} \mathrm{O} / \mathrm{m}$ for the packing height of $5 \mathrm{~cm}, 3$ $\mathrm{cm}, 2 \mathrm{~cm}$ height, respectively. The increasing of the performance of appended packing sieve tray distillation by means of the Murphee efficiency is explained by the increasing of the interfacial area for vapour-liquid than the tray itself. This preliminary study is expected to be a pioneer study of strategy to increase the performance of conventional sieve tray distillation that is known as a kind of affordable distillation process.
\end{abstract}

Keywords: sieve tray distillation, wire mesh packing, ethanol-water, Murphee efficiency

\section{Introduction}

Distillation is prime method that is commonly used in industrial separation process. In a distillation separation process, there are various types of trays that can be utilized, namely sieve tray, valve tray and bubble cap tray. Among these trays, sieve tray has received interest from both the scientific and industrial communities, due to its affordable in cost and simplicity in design (GÓrak, A., \& Olujić, Ž., 2014). Although sieve tray is of significance, the rationale design in its tray efficiency is an ongoing challenge. This challenge is generally correlated to the small interfacial area and poor tray efficiency resulted from the contact of vapour-liquid (Zuiderweg, F. J., 1982). Much effort has been devoted to answer this challenge, including the design of small hole size in sieve tray in order to produce small bubbles with large interfacial area, thus could improve the vapor-liquid contact and increase tray efficiency (Bain, J., \& Van Winkle, M., 1961; Smith, B. D., 1963). However, this effort still struggles to fully meet the feasibility in economic aspect.

In contrast to the above sieve tray distillation column, a packed distillation column has a larger interfacial area, higher efficiency, less pressure drop, and suitable for corrosive substances. But it is not suitable for low flow rates liquid. (Spagnolo, D. A., \& Chuang, K. T., 1984) are the pioneer to reveal on the possibility of combining sieve tray column with packing. To be precise, they incorporated a knitted mesh packing with bed size of $25 \mathrm{~mm}$ on the trays for the production of Girdler-Sulfide heavy water at the operating pressure and temperature of 2.17 $\mathrm{MPa}$ and $32{ }^{\circ} \mathrm{C}$, respectively, where they found increasing tray efficiency by $3-20 \%$. In particular methanol-water separation process, (Salem, A., \& Alsaygh, A. A., 1988) reported that the incorporation of 115 $\mathrm{mm}$ bed of stacked stainless steel packing on the trays increased the tray efficiency by $21 \%$. Similar system of 
methanol-water mixture was also subjected into a packed sieve tray distillation column, where a knitted mesh packing was being particularly used by Chen, G. X., et al. In their study, the Murphree tray efficiency was found to be increased, in the range of $40-50 \%$. (Kachur, P. J., et. al. 2004), studied the structured packing tray as an alternative for dual flow tray. They found that the structured packing tray was able to provide $44 \%$ improvement in capacity compared to that from dual-flow sieve tray using high liquid density systems. It also had found that its efficiency is $100 \%$ greater than the dual-flow sieve tray. (Xu, Z. P., et al., 1996) predicted the tray efficiency in relation with the addition of mesh packing in their modeling study. Similar to that of reported experimental studies, they found that the addition of mesh packing on the tray significantly increased its tray efficiency. Here the addition of packing will lead to the increase in interfacial area and vapor-liquid contact time. However, this phenomenon must be validated by the experimental studies. To the best of our knowledge, the experimental studies on validating the factors of packing on the interfacial area in sieve-tray distillation column and its corresponding efficiency have not been reported yet. Therefore, it encourages us to conduct an experimental based study with the aim to comprehend the addition of wire mesh packing with various heights on the resulting tray efficiency, and to validate the proposed factors that are responsible for the mechanism, i.e. interfacial area.

\section{Method}

In the present study, a sieve tray distillation column is modified by adding the wire mesh by means of increasing the vapor-liquid contact area in sieve tray column, thus increasing tray efficiency is expected. Here the height of wire mesh packing is varied as $5 \mathrm{~cm}, 3 \mathrm{~cm}, 2 \mathrm{~cm}$, while its void fraction and wide area are conditioned as 0.94 and $20.5 \mathrm{~cm}^{2}$, respectively. The experiment was carried out in batch system at a standard temperature and pressure condition. Ethanol and water mixture containing $10 \%$ mass of ethanol is used as feed. The wire mesh packing of having that 0.94 void fraction is only applied on the $3^{\text {rd }}$ tray to avoid weeping and flooding. The effects of the addition of wire mesh packing and its different in heights, on the resulting single tray efficiency or known as Murphee efficiency, will be the focus of this study. In a relation with Fig 1 of the schematic diagram of the experimental apparatus, the procedure is started with closing the valve and turn on the water condensor. By using batch system, E-101 is initially filled with the mixture until it reached $80 \%$ the tank volume, and then is turned on. In the control panel B-101, the boiler temperature is set up at $110^{\circ} \mathrm{C}$ and from the TC3 reading was expected in $76.8^{\circ} \mathrm{C}$ or less. This is expected to prevent water impurities in the distillate and liquid-vapour sampling. As the design sieve tray column has 2 columns, thus P-101 is needed to pump the liquid from bottom C-102 to top C-101. Until the first drop of distillate begins to form and constant, some samples are taken from GV-106 for measuring ethanol-water concentration using alcohol meter. Then, full closed GV-106 for total reflux ratio and P-102 is turned on. Apparently, $\mathrm{y}_{\mathrm{n}}, \mathrm{y}_{\mathrm{n}+1}$ and $\mathrm{x}_{\mathrm{n}}$ are required for calculating Murphee efficiency, and to do that, which some amount of sample is taken from V-102, V-103, and V-104.

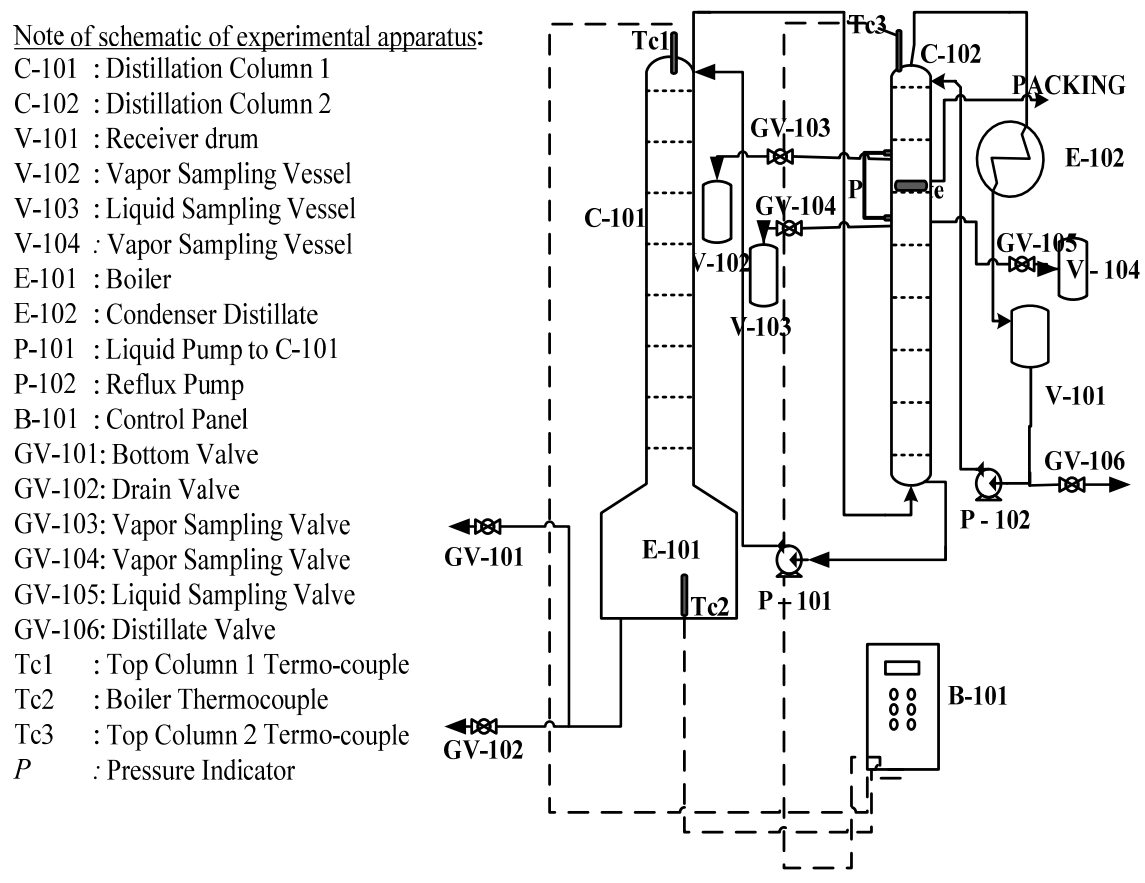

Figure 1. Schematic diagram of packed sieve trays for distillation column 

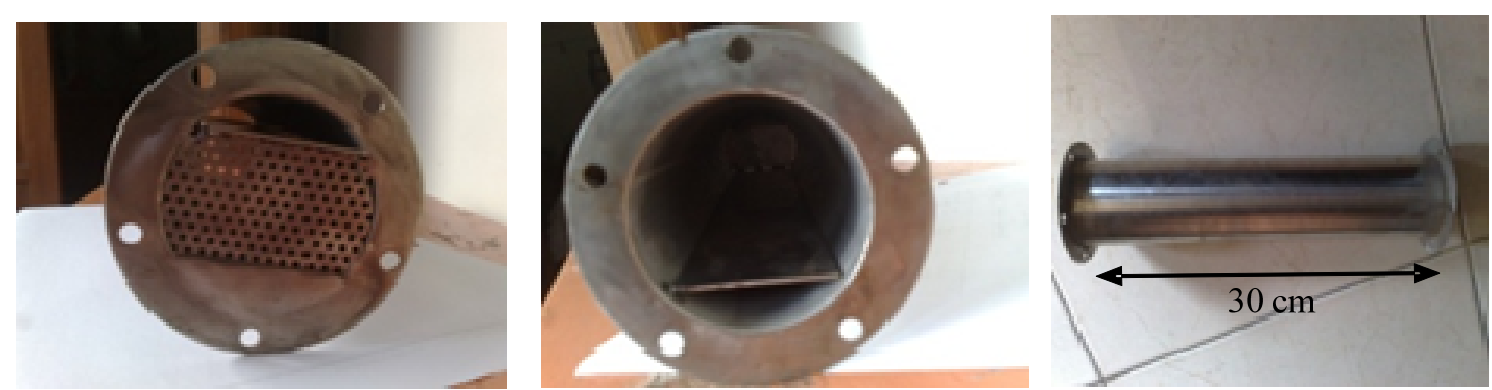

Figure 2. Snapshot photos of a single sieve tray without packing

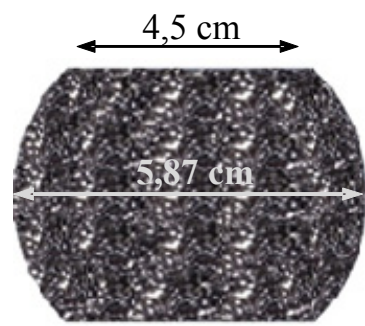

Figure 3. Wire mesh packing

Table 1. Detail dimensions of the columns and test

\begin{tabular}{ccc}
\hline No. & Parameter Dimension & Detail Dimension \\
\hline 1 & Column diameter & $5.87 \mathrm{~cm}$ \\
2 & Tray Spacing & $30 \mathrm{~cm}$ \\
3 & Hole diameter & $2 \mathrm{~mm}$ \\
4 & Column height & $2.5 \mathrm{~m}$ \\
5 & Number of tray & 16 \\
6 & Tray type & Sieve Tray \\
7 & Weir height & $5 \mathrm{~cm}$ \\
\hline
\end{tabular}

Here the interfacial area of packing is calculated from 2 step consecutive equations, i.e. equation 1 and 2 , as follows. First, specific surface area of packing is calculated by the relationship with the relative volatility, density of both vapor and liquid.

$$
\alpha=a_{p}\left[\left(1+0.78 e^{0.00058 a_{p}}\right)\left(\frac{\rho_{G}}{\rho_{L}}\right)^{0.25}\right]^{2}
$$

where $\alpha=$ relative volativity, $\rho_{\mathrm{G}}=$ density vapor $\left(\mathrm{kg} / \mathrm{m}^{3}\right), \rho_{\mathrm{L}}=$ density liqud $\left(\mathrm{kg} / \mathrm{m}^{3}\right)$, and $\mathrm{a}_{\mathrm{p}}=$ specific surface area of packing $\left(\mathrm{cm}^{2} / \mathrm{cm}^{3}\right)$. After obtaining the specific surface area of packing, look for the interfacial area obtained by the following equation (McCabe, W. L. et al., 2001, Van Winkle, M., 1967):

$$
a_{W}=a_{p}\left\{1-\exp \left[-1,45 \cdot \operatorname{Re}_{L}^{0.1} \cdot F r_{L}^{-0.05} \cdot W e_{L}^{0.2} \cdot\left(\frac{\sigma}{\sigma_{C}}\right)^{-0.75}\right]\right\}
$$

With $\mathrm{Re}_{L}, \mathrm{We}_{L}$, and $\mathrm{Fr}_{L}$ are described as follows.

$$
\begin{aligned}
& \operatorname{Re}_{L}=\frac{G_{L}}{a_{p} \cdot \mu_{L}} \\
& W e_{L}=\frac{G_{L}{ }^{2}}{a_{p} \cdot \sigma \cdot \rho_{L}}
\end{aligned}
$$




$$
F r_{L}=\frac{a_{p} \cdot G_{L}^{2}}{g \cdot \rho_{L}^{2}}
$$

where $a_{w}=$ Wetted (interfacial) surface area of packing (m), $R e_{L}=$ Reynolds number for liquid, $F r_{L}=$ Froude number for liquid, $W e_{L}=$ Weber number for liquid, $G_{L}=$ Liquid mass flow $(\mathrm{kg} / \mathrm{h} . \mathrm{m}), S=$ Surface tension $(\mathrm{N} / \mathrm{m})$, $\mu_{L}=$ Viscosity of liquid ( $\left.\mathrm{kg} / \mathrm{m} . \mathrm{s}\right), a_{p}=$ Specific surface of packing $\left(\mathrm{cm}^{2} / \mathrm{cm}^{3}\right)$, and $g=$ Gravity acceleration.

Based on the data of interfacial area, the vapor velocity in each packing height can be the obtained. Several calculation steps must be carried out, first step is to calculate effective particle diameter by assuming that the shape factor of particular packing is 0.87 (based on shape factor of cylinder packing.

$$
D_{p}=\frac{6}{\varphi_{S} a_{v}}
$$

Second step is to substitute the obtained effective particle diameter, the viscosity and density of vapor, the measured pressure drop, the void fraction and height of the packing, into the Ergun equation, to obtain vapor velocity by trial method (Geankoplis, C. J., 1993).

$$
\Delta p=\frac{150 \mu v^{\prime} \Delta L}{D_{p}{ }^{2}} \frac{\left(1-\varepsilon^{2}\right)}{\varepsilon^{3}}+\frac{1.75 \rho\left(v^{\prime}\right)^{2} \Delta L}{D_{p}} \cdot \frac{1-\varepsilon}{\varepsilon^{3}}
$$

where $a_{v}=$ Interfacial area $\left(\mathrm{cm}^{2} / \mathrm{cm}^{3}\right), \Phi_{S}=$ Shape factor, $\Delta P=$ Pressure drop $\left(\mathrm{N} / \mathrm{m}^{2}\right), \mu=$ Viscosity of vapor $(\mathrm{kg} / \mathrm{m} . \mathrm{s}), \mathrm{v}^{\prime}=$ Vapor velocity $(\mathrm{m} / \mathrm{s}), \Delta \mathrm{L}=$ Packing height $(\mathrm{m}), \varepsilon=$ Void fraction

\section{Results and Discussion}

Figure 4 shows the effects of packing heights on their corresponding interfacial areas. As can be seen from this figure, the interfacial area were found to be $11.88 \mathrm{~cm}^{2} / \mathrm{cm}^{3}, 0.48 \mathrm{~cm}^{2} / \mathrm{cm}^{3}$, and $0.32 \mathrm{~cm}^{2} / \mathrm{cm}^{3}$ for the packing height of $5 \mathrm{~cm}, 3 \mathrm{~cm}, 2 \mathrm{~cm}$ height, respectively. The increasing of interfacial area is affected by the increasing of packing height, with higher packing height tend to have better liquid-vapor contact. This can be explained by the fact that presence of mesh-packed tray would tend to generate uniform smaller bubbles compared to that of from sieve tray only, which is usually followed by an increase in interfacial area. (Chen, G. X., et al., 1992).

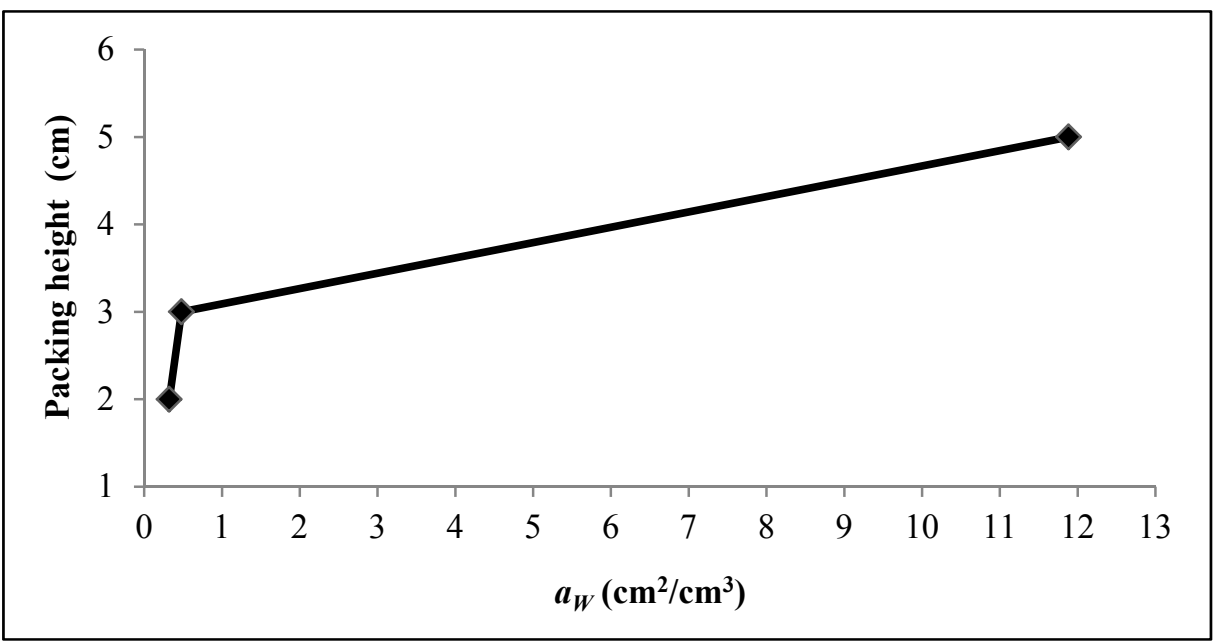

Figure 4. Interfacial area with different height

Figure 5 shows the effects of packing heights on their corresponding Murphee efficiencies. To obtain the Murphee efficiency itself, the samples from yn, yn+1 and xn must be taken. Here the yn is mole fraction of more volatile component from vapor stream above the tray while for that of $y n+1$ is from below the tray. The $y n^{*}$ is mole fraction of the vapour stream above the tray, which is in equilibrium with its liquid stream (Perry, R., et al., 1997). Using the ethanol-water equilibrium curve, the $\mathrm{yn}^{*}$ is obtained from the data of $\mathrm{xn}$, which is measured from the experiment. In detailed observation in this figure, the Murphee efficiency (EMV) is found to be increased by the increase in packing height. To be specific, EMV of $47 \%$ is obtained from tray without packing; while the EMV of $74 \%$ is obtained from tray with $5 \mathrm{~cm}$ packing height, which means there is an increase in 
efficiency of $58 \%$ from $47 \%$. EMV of $66 \%$ is obtained from tray with $3 \mathrm{~cm}$ packing height, which means there is an increased efficiency of $42 \%$ from $47 \%$. For the smallest packing with $2 \mathrm{~cm}$ height of having EMV of $57 \%$, it is found that an increased EMV of $22 \%$ from $47 \%$. In general, overall Murphee efficiency increased in between 21-57\% compared to that of without packing. This increase in Murphee efficiency can be explained by the fact that the addition of packing enhances the contat between liquid-vapor, as explained in Figure 4. Also, the froth with smaller bubble size tends to have a higher surface tension (Spagnolo, D. A., et al., 1984).

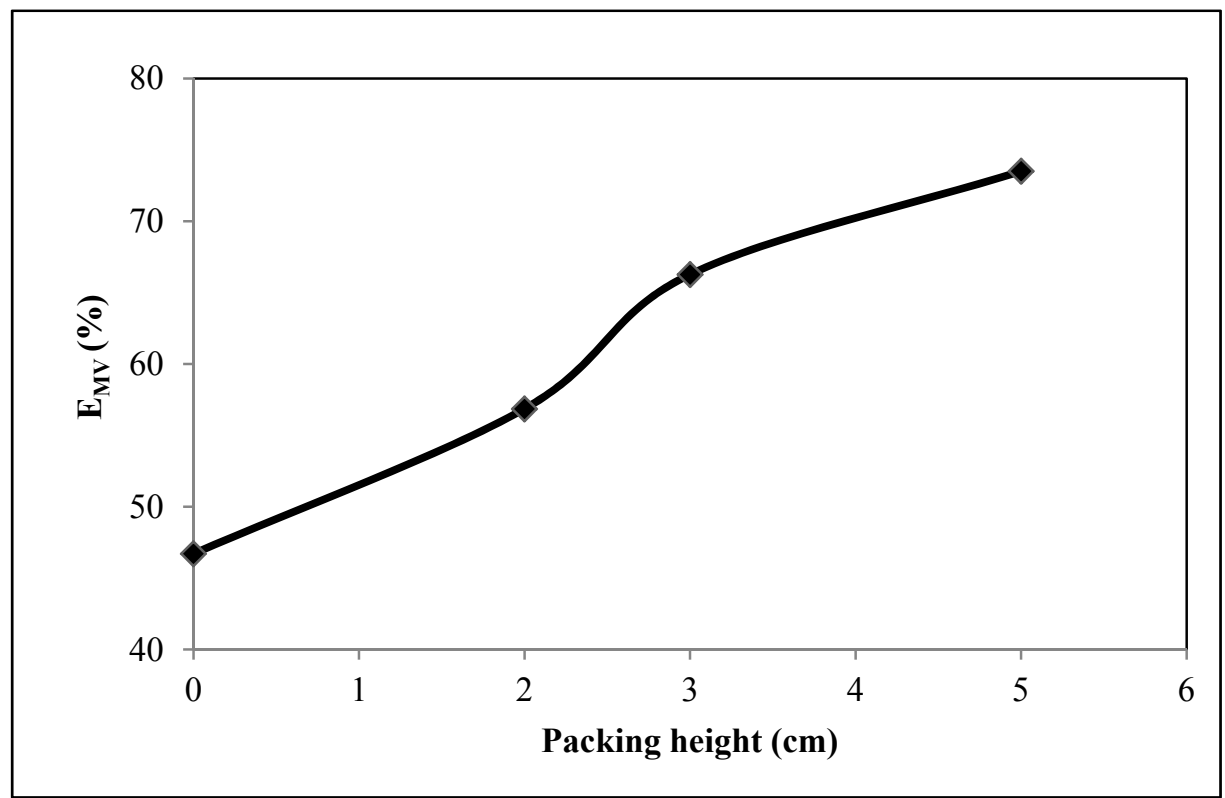

Figure 5. EMV(\%) result from different packing height $(\mathrm{cm})$

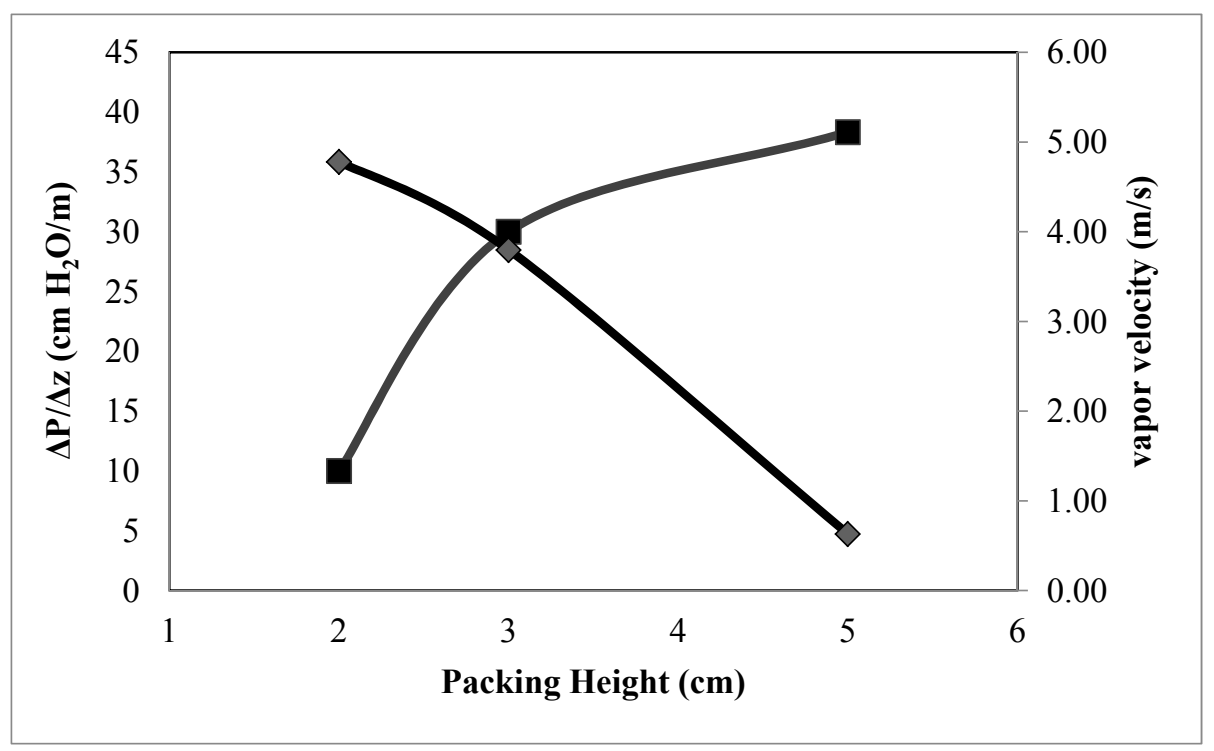

Figure 6. Measured $\Delta \mathrm{P} / \Delta \mathrm{Z}(\mathrm{cm} \mathrm{H} 2 \mathrm{O} / \mathrm{m})$ and vapor velocity $(\mathrm{m} / \mathrm{s})$ from different packing height $(\mathrm{cm})$

From Figure.6 explained that pressure drop measured from the water manomater height were $38.33 \mathrm{~cm} \mathrm{H}_{2} \mathrm{O} / \mathrm{m}$, $30 \mathrm{~cm} \mathrm{H}$ O/m, $10 \mathrm{~cm} \mathrm{H}_{2} \mathrm{O} / \mathrm{m}$ for the packing height of $5 \mathrm{~cm}, 3 \mathrm{~cm}, 2 \mathrm{~cm}$ height, respectively. This indicates that the mass transfer effciency is very high in the packing zone because of the large interfacial area. Pressure drop increased along with the increasing interfacial area (Chen, G. X., et al., 1992).

Nevertheless, significant difference in pressure drop is shown for packing with $2 \mathrm{~cm}$ and $3 \mathrm{~cm}$ height, as explained before in Figure.4, where it can be correlated by the gradient in interfacial area. According to Chen, G. $\mathrm{X}$., et al., the presence of mesh packing in sieve tray column showed a lower weeping and entrainment effects, 
yet showed a higher froth and pressure drop effects. The effects of entrainment and weeping could be suppressed because of the presence of mesh packing could break up the vapor into smaller size and stabilize the bubbles, thus in effect the vapor could flow through to the next tray. If some liquid also brought by the vapor through the next tray, this would decrease the Murphee efficiency. Higher froth height would prevents the liquid to fall through the next below tray, and thus could lower the weeping effect.

Figure 6 also explained the correlation between packing height and vapor velocity. According to Ergun equation (Geankoplis, C. J., 1993) that is applicable in low, intermediate, and high Reynolds numbers, the vapor velocity were found to $0.63 \mathrm{~m} / \mathrm{s}, 3.8 \mathrm{~m} / \mathrm{s}, 4.76 \mathrm{~m} / \mathrm{s}$ for the packing height of $5 \mathrm{~cm}, 3 \mathrm{~cm}, 2 \mathrm{~cm}$ height, respectively. This means the increase in packing height will result in decrease in vapor velocity. This finding is consistent with the previous discussion on interfacial area (see discussion on Figure 4). The increase in packing height will tend to improve the liquid-vapor contact, by making a uniform and stable small bubbles result. This will also result in increase in froth height and residence time, thus it gives an increase in pressure drop.

\section{Acknowledgments}

The authors would like to thank the Sepuluh Nopember Institute of Technology (ITS) and the Indonesian Directorate General of Higher Education (DIKTI) for the financial supports, under the financial scheme of BOPTN ITS with contract number of 016452.23/IT2.7/PN.01.00/2014 and 003246.149/IT2.11/PN.08/2015.

\section{References}

Bain, J., \& M. Van Winkle. (1961). A Study of Entrainment, Perforated Plate Column-Air-Water System. AIChE, 7(3), 363-366. http://dx.doi.org/10.1002/aic.690070304

Chen, G. X., Afacan, A., Xu, C., \& Chuang, K. T. (1990). Performance of Combined Mesh Packing and Sieve Tray in Distillation. The Canadian Journal of Chemical Engineering, 68(3), 382-385. http://dx.doi.org/10.1002/cjce.5450680305

Chen, G. X., Chuang, K. T., Chien, C., \& Ye, Y. (1992). Mass Transfer and Hydraulic of Packed Sieve Tray. Gas Separation and Purification, 6(4), 208-212. http://dx.doi.org/10.1016/0950-4214(92)80024-D

Geankoplis, C. J. (1993). Transport Processes and Unit Operations (3rd ed.). America: Prentice-Hall, Inc.

Górak, A., \& Olujić, Ž. (2014). Distillation: Equipment and Processes. Oxford, UK: Academic Press

Kachur, P. J., Afacan, A., \& Chuang, K. T. (2004). Use of Structured Packing As a Dualflow Tray in Distillation. $\begin{array}{llll}\text { Chemical Engineering Research } & \text { 813-820. }\end{array}$ http://dx.doi.org/10.1205/0263876041596643

McCabe, W. L., Smith, J. C., \& Harriot, P. (2001). Unit Operations of Chemical Engineering (6 ${ }^{\text {th }}$ Edition). New York: McGraw-Hill Book Company

Perry, R., \& Chilton, C. (1997). Chemical Engineer's Handbook (6th ed.). New York: Mc. Graw Hill Book Company, Inc.

Salem, A., \& Alsaygh, A. A. (1988). Better Sieve Tray Add Packing. Hydrocarbon Processing, 67(5), G-H.

Smith, B. D. (1963). Design of Equilibrium Stage Proceses. New York: McGraw-Hill Book Company.

Spagnolo, D. A., \& Chuang, K. T. (1984). Improving Sieve Tray Performance with Knitted Mesh Packing. Industrial \& Engineering Chemistry Process Design and Development, 23(3), 561-565. http://dx.doi.org/10.1021/i200026a026

Van Winkle, M. (1967). Distillation. New York: McGraw-Hill Book Company.

Xu, Z. P., Afacan, A., K. T., \& Chuang, K. T. (1996). Prediction of Packed Sieve Tray Efficiency in Distillation. Chemical Engineering Research and Design, 74(8), 893-900. http://dx.doi.org/10.1205/026387696523193

Zuiderweg, F. I. (1982). Sieve Trays: A View on the state of the art. Chemical Engineering Science, 37(10), 1441-1464. http://dx.doi.org/doi:10.1016/0009-2509(82)80001-8

\section{Copyrights}

Copyright for this article is retained by the author(s), with first publication rights granted to the journal.

This is an open-access article distributed under the terms and conditions of the Creative Commons Attribution license (http://creativecommons.org/licenses/by/3.0/). 